Cahiers $d u$ MONDE RUSSE

\section{Cahiers du monde russe}

Russie - Empire russe - Union soviétique et États indépendants

$43 / 4 \mid 2002$

Intellectuels et intelligentsia

\title{
Jean-Paul Depretto, Pouvoirs et société en Union Soviétique
}

\section{Nicolas Werth}

\section{OpenEdition}

Journals

Édition électronique

URL : https://journals.openedition.org/monderusse/4024

DOI : $10.4000 /$ monderusse. 4024

ISSN : $1777-5388$

\section{Éditeur}

Éditions de l'EHESS

\section{Édition imprimée}

Date de publication : 30 décembre 2002

Pagination : 713-714

ISBN : 2-7132-1796-2

ISSN : $1252-6576$

Référence électronique

Nicolas Werth, « Jean-Paul Depretto, Pouvoirs et société en Union Soviétique », Cahiers du monde russe [En ligne], 43/4 | 2002, mis en ligne le 17 juin 2009, consulté le 02 septembre 2022. URL : http:// journals.openedition.org/monderusse/4024; DOI : https://doi.org/10.4000/monderusse.4024

Ce document a été généré automatiquement le 2 septembre 2022

Tous droits réservés 


\title{
Jean-Paul Depretto, Pouvoirs et société en Union Soviétique
}

\author{
Nicolas Werth
}

\section{RÉFÉRENCE}

Jean-Paul DEPRETTO, Pouvoirs et société en Union Soviétique. Paris, Éditions de l'Atelier/Éditions ouvrières, 2002, 207 p.

1 Comme la plupart des recueils d'articles écrits par des auteurs divers et rassemblés $a$ posteriori, celui qu'a constitué Jean-Paul Depretto ne présente pas, de prime abord, une grande homogénéité. Ce défaut, inhérent au genre, ne nuit en rien à la qualité de l'ensemble, la plupart des articles apportant, chacun sur un champ d'étude précis, une analyse pertinente. Dans la continuité de sa contribution sur la violence (Le siècle des communismes), Peter Holquist met l'accent sur le rôle crucial des années de guerre 1914-1917, qui virent la naissance d'un « complexe para-étatique » : pour comprendre l'étatisme bolchevik, il faut l'inscrire dans un courant plus large, celui de la culture politique des élites éduquées, favorables à une intervention toujours plus grande de l'État dans la sphère sociale et économique. Si cette thèse, qui n'est pas nouvelle (elle fut largement développée dans les années 1920 dans certains milieux de l'émigration), paraît solidement étayée dans un certain nombre d'articles récents de Peter Holquist, il faut se garder de perdre, dans la démonstration, la spécificité idéologique propre au bolchevisme et de minimiser les différences fondamentales qui séparaient le discours des experts non bolcheviks et les pratiques politiques bolcheviques.

2 L'article de Martine Mespoulet sur le milieu des statisticiens de la région de Saratov montre de manière convaincante comment un milieu professionnel de l'Ancien Régime est parvenu, tout au long des années 1920, à sauvegarder ses " espaces d'autonomie ", ses logiques professionnelles et son unité de corps face aux logiques politiques des représentants locaux du nouveau pouvoir bolchevik. L'autre article du recueil consacré aux années 1920 ( « Les conflits du travail en Russie soviétique pendant le "communisme 
de guerre" et la NEP») paraît plus convenu, surtout pour la période 1918-1922, largement renouvelée - pour ce qui concerne les conflits entre le régime et le monde ouvrier - par les travaux de Vladimir Brovkin ou d'Andrea Graziosi. Dans un article consacré à la privation des droits civiques dans un quartier de Moscou à la fin des années 1920, Nathalie Moine, dans le sillage de Golfo Alexopoulos, analyse avec finesse la sociologie et les stratégies discursives d'un échantillon de Moscovites, pour l'essentiel issus de milieux populaires, privés de leurs droits civiques. Dans cet essai de micro-histoire, elle met bien en évidence les contradictions et les incohérences entre des catégories d'exclusion élaborées par le pouvoir central, la mise en œuvre d'une politique par les autorités locales et des situations individuelles résistant à toute catégorisation rigide.

3 L'article d'Elena Osokina sur la crise du ravitaillement de 1939-1941, un épisode mal connu, est particulièrement remarquable. Développant le dernier chapitre de son ouvrage sur le système de rationnement et de distribution, récemment traduit en anglais, Elena Osokina brosse un tableau stupéfiant de la situation de crise dans les villes soviétiques à la veille de la guerre. Face aux pénuries extrêmes, les citoyens tentent de s'organiser eux-mêmes, au niveau du quartier, établissant des normes d'achat, organisant les files d'attente, chassant « étrangers » et intrus, mettant en place, à la base, une forme de "rationnement sauvage", avant que les autorités politiques se décident enfin à officialiser, en juillet 1941, un système centralisé de rationnement.

On regrettera, dans ce recueil consacré, comme l'annonce la quatrième de couverture, $\mathrm{au}$ « thème de la confrontation entre les différentes formes du pouvoir soviétique et de la société d'avant-guerre ", l'absence de tout article sur la paysannerie ou sur les formes massives - et extrêmes - de violence exercées sur la société, telles que la famine ou les quotas d'exécution des années 1937-1938. Décidément l'histoire sociale, l'histoire "vue d'en bas" - même la meilleure, comme celle présentée dans ce recueil - semble réticente à aborder un certain nombre de questions qui individualisent, de manière forte et radicale, l'URSS stalinienne. 